\title{
MANEJO DO ALEITAMENTO MATERNO DE FORMA LÚDICA EM SALAS DE APOIO À AMAMENTAÇÃO
}

Fabíula Ferreira Gomes da Silva'; Isabela Rodrigues Barroso²; Melissa Soares

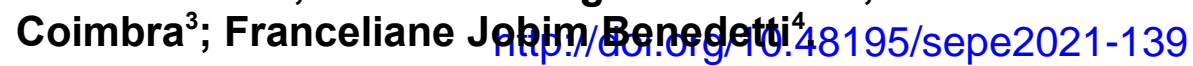

\section{RESUMO}

O aleitamento materno é de suma importância tanto para as mães, quanto para os seus bebês. Temos consciência de que a falta de informação ainda é um problema na nossa sociedade, assim como o tabu da amamentação. Desta forma o objetivo desse projeto é ensinar de forma lúdica o manejo e posição correta do aleitamento às lactantes voluntárias. Este trabalho busca relatar a experiência vivida em uma Sala de Apoio à Amamentação de uma universidade privada, e foi construído a partir do projeto de extensão da cadeira Nutrição Materno Infantil da Universidade Franciscana. A partir da atividade, foi desenvolvido um boneco para explicação do manejo correto, referenciando um bebê de tamanho e peso real; o mesmo foi doado para o Espaço Amamentação da UFN após as atividades, para que mais alunos e usuárias possam se beneficiar.

Palavras-chave: Saúde; Nutrição; Amamentação; Nutriz; Puerpério.

Eixo Temático: Atenção Integral e Promoção à Saúde (AIPS).

\section{INTRODUÇÃO}

A saúde de grávidas e bebês é prioritário no Sistema Único de Saúde (SUS), e segundo o Ministério da Saúde, o Programa de Atenção e Saúde da Família deve ser estratégico em consonância aos riscos deste período, promovendo assim, políticas públicas de saúde coletiva (GOMES, et al. 2019). Segundo o Ministério da Saúde (2011), o profissional de saúde tem papel fundamental na promoção, proteção e apoio ao Aleitamento Materno. Para exercer esse papel ele precisa, além do conhecimento e de habilidades relacionados a aspectos técnicos da lactação, ter um olhar atento, abrangente, sempre levando em consideração os aspectos emocionais, a cultura familiar, a rede social de apoio à mulher, entre outros aspectos.

A grande maioria das mães tem conhecimento da importância do aleitamento materno, porém em 2021 ainda é considerado tabu ver mulheres amamentando seus filhos em público, com isso começa o desconforto da mãe que maleficia a posição correta do aleitamento. Sendo assim, muitas mães desconhecem a posição correta e até mesmo que exista uma, pois o primeiro passo de se manter relaxada e confortável não é efetuado. $O$ trabalho de orientação da 
técnica de posicionamento e pega do recém-nascido das gestantes e puérperas auxiliam a tornar mais fácil este momento e também a maior adesão para a amamentação (LUCAS, F. 2014).

Mesmo com o alto nível de informações que temos atualmente, muitas vezes a lactante não relata suas dúvidas com alguém que tenha conhecimento sobre o assunto, leva em consideração os registros que constam na internet, redes sociais e até mesmo com parentes que já estiveram na mesma situação. Essa "vergonha" de perguntar, ou a falta de acesso para chegar até pessoas que têm conhecimento do assunto, podem gerar problemas no momento da amamentação, principalmente em mães de "primeira viagem".

As salas de apoio a amamentação trazem um somatório para a sociedade, visto que não é somente o binômio mãe-filho que se beneficia, mas todos que investem nessa estratégia. Fernandes, et al. (2016) descrevem a necessidade das salas de amamentação, apresentando tópicos como: manter a produção do leite, proporcionar o alívio do desconforto das mamas que ingurgitam durante o longo período que passam no trabalho e o armazenamento correto do leite materno, com vistas à alimentação do seu próprio filho ou para doação a um banco de leite humano.

O bem-estar, conforto e paciência da lactante são de suma importância na hora da amamentação que, juntamente com seu manejo apropriado tem inúmeros benefícios. Os benefícios da "pega" não são vistos somente com a nutriz, mas também o bebê que está recebendo o aleitamento, tem menos risco de se engasgar, evita trauma mamilar, refluxo, vômitos, entre outros.

A mamada além de proporcionar a alimentação da criança, deve ser a construção de um vínculo entre mãe e filho. Para COCA, K. et al. (2009), entre as posições existem variáveis comuns da criança como pescoço torcido, queixo, distância da mama e lábio. Diante dessas afirmações observa-se a ressalta da chegada dessas informações para a puérpera como parte da assistência devida à saúde da mulher. 
Com o material elaborado espera-se ensinar de forma lúdica o manejo e posição correta do aleitamento as lactantes voluntárias do "Espaço Amamentação" da Universidade Franciscana.

\section{METODOLOGIA}

O presente trabalho trata-se de um relato de experiência, foi desenvolvido a partir do projeto de extensão da disciplina Nutrição Materno Infantil do Curso de Nutrição, da Universidade Franciscana (UFN). Devido a pandemia de COVID-19, as atividades ocorreram de forma hibrida, através da plataforma Microsoft Teams ${ }^{\circledR}$, e encontros presenciais para atividades práticas e atendimentos no Espaço Amamentação da UFN. O tema do projeto de extensão foi o aleitamento materno, e teve como título "Amamentar para Viver". Foi durante o desenvolvimento do projeto que encontramos uma forma de explicar as posições corretas da pega de maneira simples e visual por meio de um boneco didático, confeccionado pelos acadêmicos.

O boneco desenvolvido teve o comprimento de $56 \mathrm{~cm}$, pesando em torno de 2,5kg, para que seu peso e estatura se aproximassem de um bebê recém-nascido, foi feito de tecido plastificado para fácil higienização devido a pandemia de COVID19, e sua cabeça foi feita sem sustentação para que ficasse o mais realista possível no momento das demonstrações e manejo. A foto do boneco didático encontra-se a seguir:

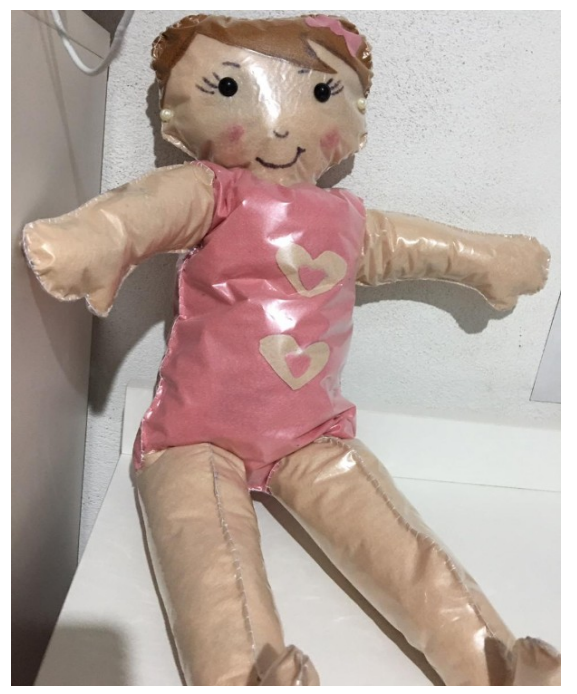


Também foi confecionado um poster informativo, de tamanho significativo, para posterior exposição em frente ao Espaço Amamentação da UFN, onde constavam algumas informações necessárias para o momento do manejo do bebê. Essas informações foram retiradas dos materiais do Ministério da Saúde como o Guia Alimentar para Crianças Menores de 2 Anos (BRASIL, 2019), e também de artigos científicos que abordam o tema. Apresentamos nesse poster, posições importantes de serem lembradas, assim como a forma correta de o bebê fazer a pega no seio materno; mostramos que a amamentação deve ser feita sempre de uma forma confortável, com apoio para as costas e para apioar o bebê; também apresentamos alguns alimentos que devem receber uma maior atenção durante o período, e sobre as quantidades de leite materno que o bebê deve receber nos primeiros meses de vida, sempre atentando que deve ser em livre demanda, conforme o bebê apresentar desejo ou solicitar.

No poster, deixamos claro sobre como esse período deve ser: leve, delicado e feito com carinho; para que qualquer mulher que fosse ler o informativo, se sentisse acolhida.

\section{RESULTADOS E DISCUSSÕES}

Os atendimentos do curso de Nutrição da UFN ocorreram durante o semestre; o boneco foi utilizado para atividades em sala de aula, e posteriormente doado para - Espaço Amamentação, para que mais pessoas, sendo alunos ou usuárias do espaço, se beneficiem da atividade.

Ao longo do semestre os acadêmicos pesquisaram por diversos meios, formas de atingir o público-alvo através de atividades lúdicas que envolvessem os temas abordados em aula, e assim que possível, desenvolvêssemos atividades na sala de apoio à amamentação junto com mães de "primeira-viagem", gestantes e também quem encontra-se em fase de amamentação.

\section{CONCLUSÃO}

Fazer a explanação de como deve ocorrer o manejo, e a pega do bebê no momento da amamentação, é muito importante. Muitas mães ainda não se sentem confortáveis de amamentar em público, outras tem dúvidas, algumas não entendem 
EDUCAÇÃO, SAÚDE

ETECNOLOGIA

26 A 28 DE OUTUBRO DE 2021

a importância do aleitamento materno. Como alunos do curso de Nutrição e futuros profissionais da área da saúde, nos sentimos no dever de apresentar as maneiras corretas para o bebê fazer a pega, ensinarmos as posições e formas de manejo corretas nesse momento tão bonito. Sendo assim, as demonstrações com o boneco desenvolvido pelos alunos foram de suma importância para que houvesse um melhor entendimento das usuárias do Espaço Amamentação.

\section{AGRADECIMENTOS}

Agradecemos à Universidade Franciscana pela oportunidade de participar do evento e de nos permitir expor nosso projeto, o qual foi feito com muito carinho. Assim como, agradecemos a professora Franceliane Jobim pelo apoio e pela paciência em nos orientar; ao curso de Nutrição e ao Mestrado em Saúde Materno Infantil pelo apoio e parceria nas atividades que envolveram o Espaço Amamentação.

\section{REFERÊNCIAS}

BELLO, A. Um guia prático sobre amamentação. Rev. Annie Bello, nutrição baseada em evidência. Rio de Janeiro. 2018.

BRASIL, Ministério da Saúde. Saúde da mulher na gestação, parto e puerpério. Sociedade Beneficente Israelita Brasileira Albert Einstein. São Paulo: Hospital Israelita Albert Einstein. 2019.

BRASIL, Ministério da Saúde. Secretaria de Atenção à Saúde. Departamento de Ações Programáticas e Estratégicas. Atenção à saúde do recém-nascido: guia para os profissionais de saúde. Brasília. 2011. 
BRASIL, Ministério da Saúde. Secretaria de Atenção Primária a Saúde. Departamento da Promoção a Saúde. Guia alimentar para crianças brasileiras menores de 2 anos. Brasília, 2019.

BUSTAMENTE, V.; McCALUM, A, C. O cuidado de grávidas e bebês no contexto do Programa de Saúde da Família. Interface vol. 5. Botucatu. 2010.

COCA, K. et al. A posição de amamentar determina o aparecimento do trauma alimentar? Rev. Esc. Enfermagem USP. São Paulo, 2009.

CONSOLINI, D, M. Aleitamento materno. Sidney Kimmel Medical College of Thomas Jefferson University. 2019.

FERNANDES, VMB. et al. A importância das salas de apoio a amamentação nos locais de trabalho. Rev Gaúcha Enferm. 2016.

KALIL, R, I.; AGUIAR, C, A. Protagonista da amamentação ou Instrumento da política de saúde infantil: a enunciação da mulher nos materiais oficiais de promoção e orientação ao aleitamento materno. São Paulo, 2016.

LUCAS, F. Aleitamento materno: posicionamento e pega adequada do recémnascido. Universidade Federal de Minas Gerais. Curso de especialização estratégia saúde da família. 2014.

Manual de Normas e Rotinas de Aleitamento Materno do HU-UFGD/EBSERH, 2017. Boletim de Serviço $n^{\circ} 178$, de 25 de fevereiro de 2019, anexo à Portaria $n^{\circ} 22$.

SANCHES, M, T. Manejo clínico das disfunções orais na amamentação. Jornal de Pediatria, vol. n80. São Paulo, 2004. 